\title{
The TMS Foundation: A Great Growth Investment in the Future of MSE
}

\author{
Elizabeth Holm
}

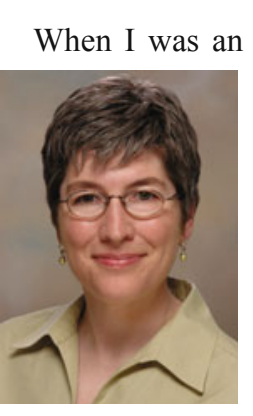

Elizabeth Holm undergraduate student at the University of Michigan, I received a scholarship from the Michigan Society of Professional Engineers (MSPE). Even way back then, tuition was a large expense, so I certainly appreciated the financial aid. What makes that scholarship truly memorable, however, is that it was awarded at an MSPE dinner meeting. At a time when engineering was uncharted territory for me, being included as a member of the engineering community was an important milestone. From my point of view, MSPE's investment paid itself off many times over.

Now that I am a more senior member of our profession, I realize that students need every bit as much tangible and intangible support as I did almost 30 years ago. And as an educator and engineer, I want to do everything possible to ensure success in their careers. During my term as TMS president, it has become very clear to me that supporting the work of the TMS Foundation is a significant way to make a difference in the futures of many of these aspiring materials science and engineering (MSE) professionals.

The mission of the TMS Foundation is to "develop and fund programs that will fully prepare future generations of professionals for leadership roles in the international minerals, metals, and materials community." While those words accurately describe the "what" of the Foundation, I'd like to share some insights about the "why":

"This scholarship is a tremendous encouragement to me. It makes me realize my potential to contribute to future work in materials science." (Zixing Wang, University of Illinois, 2014 Extraction \& Processing Division Scholarship Recipient)

"This award shows that others are willing to invest in my future." (Caleb Felker, University of Alabama, 2014 Light Metals Division Scholarship Recipient)

"Not so long ago I was a timid college freshman, unsure about my chosen field of materials science and the research career I intended to pursue. To be awarded this scholarship, based on the merit of my research and scholastic endeavors, is deeply meaningful to me." (Patrick Shower, Georgia Institute of Technology, 2014 Structural Materials Division Scholarship Recipient)

There are many, many more stories just like these, stretching back over the lifetime of the TMS Foundation.

While students obviously appreciate the financial support, many of the Foundation's programs - travel grants, poster competitions, and best paper contests among them-seek to forge the professional connections and recognition that are so important to the newest members of our profession.

TMS Foundation programs also extend beyond the student years. For early career professionals, the Young Leader Professional Development Award and Early Career Faculty Fellow Award facilitate networking at the TMS Annual Meeting, while also grooming the recipients for future leadership positions in the field. The Foundation also enables promising young professionals to participate in the Emerging Leaders Alliance, and through its relationship with the Japan Institute of Metals (JIM) and the Federation of European Materials Societies (FEMS), has opened doors to global collaborations through highly successful exchange programs, not only benefiting the researchers involved, but also advancing progress of the international MSE community.

This is not a comprehensive catalog of the TMS Foundation's work, but I hope it offers enough for you to appreciate the Foundation's far-reaching impact. To build on this momentum, the TMS Foundation Board of Trustees recently initiated the TMS Foundation Growth Project to expand Foundation programs and resources. I want to gratefully acknowledge the commitment and creativity of the members of the Foundation Revitalization Committee and Young Professionals Program Development Committee who participated in this important endeavor. They spent long hours crafting new avenues of benefit for the Foundation, which we will act upon in the coming year.

In the meantime, the TMS Foundation will continue to generate more compelling stories of how meaningful support can make a significant difference in the lives of individuals and the future of our profession. To be part of those stories, I encourage you to consider the TMS Foundation for a charitable gift — and a growth investment in the future of MSE.

Elizabeth Holm is a professor with the Department of Materials Science \& Engineering, Carnegie Mellon University, Pittsburgh, PA and the 2013 TMS president. 